\title{
ATP binding cassette transporter gene expression in rat liver progenitor cells
}

\author{
J E Ros, T A D Roskams, M Geuken, R Havinga, P L Splinter, B E Petersen, N F LaRusso, \\ D $M$ van der Kolk, F Kuipers, K N Faber, M Müller, P L M Jansen
}

See end of article for authors' affiliations

Correspondence to: P L M Jansen, University Hospital Groningen, Department of Internal Medicine, Division of Gastroenterology and Hepatology, PO Box 30.001, 9700 RB Groningen, the Netherlands;

p.l.m.jansen@int.azg.nl

Accepted for publication 2 January 2003
Background and aim: Liver regeneration after severe liver damage depends in part on proliferation and differentiation of hepatic progenitor cells (HPCs). Under these conditions they must be able to withstand the toxic milieu of the damaged liver. ATP binding cassette $(A B C)$ transporters are cytoprotective efflux pumps that may contribute to the preservation of these cells. The aim of this study was to determine the $A B C$ transporter phenotype of HPCs.

Methods: HPC activation was studied in rats treated with 2- acetylaminofluorene (2-AAF) followed by partial hepatectomy $(\mathrm{PH})$. $A B C$ transporter gene expression was determined by real time detection reverse transcription-polymerase chain reaction in isolated HPCs, hepatocytes, cholangiocytes, and cultured progenitor cell-like RLF $\phi 13$ cells and by immunohistochemistry of total liver samples. ABC transporter efflux activity was studied in RLF $\phi 13$ cells by flow cytometry.

Results: 2-AAF/PHx treated animals showed increased hepatic mRNA levels of the genes encoding multidrug resistance proteins Mdrlb, Mrpl, and Mrp3. Immunohistochemistry demonstrated expression of Mrpl and Mrp3 proteins in periportal progenitor cells and of the Mdr1b protein in periportal hepatocytes. Freshly isolated Thy- 1 positive cells and cultured RLF $\phi 13$ progenitor cells highly expressed Mrp 1 and Mrp3 mRNA while the hepatocyte specific transporters Mdr2, Bsep, Mrp2, and Mrp6 were only minimally expressed. Blocking Mrp activity by MK-571 resulted in accumulation of the Mrp specific substrate carboxyfluorescein in RLF $\phi 13$ cells

Conclusion: HPCs express high levels of active Mrpl and Mrp3. These may have a cytoprotective role in conditions of severe hepatotoxicity. iver regeneration occurs after loss of liver tissue due to toxic injury or partial hepatectomy (PHx) and is predominantly accomplished by replication of hepatocytes. Under conditions in which hepatocytes cannot proliferate, liver damage results in activation of the hepatic progenitor cell (HPC) compartment. ${ }^{1}$ In humans, this occurs during severe liver injury when a significant number of hepatocytes are lost. In rats, HPC proliferation can be achieved by treatment with 2 -acetylaminofluorene (2-AAF) in combination with $\mathrm{PHx}$ or carbon tetrachloride $\left(\mathrm{CCl}_{4}\right)$ administration. Treatment with 2-AAF followed by PHx causes a block in hepatocyte proliferation at the Gl/S restriction point due to decreased expression of cyclin E and increased hepatocytic expression of p53 and p2 $1 .{ }^{2}$ HPCs, located in the canals of Hering, ${ }^{3}$ escape from the 2-AAF induced blockade and proliferate in the 2-AAF/PHx model. Their proliferation reaches a maximal level 9-11 days after hepatic injury. ${ }^{4}$ HPCs resemble fetal hepatic cells as they express fetal markers such as $\alpha$-fetoprotein and Thy- 1 at high levels and are considered to be the bipotential precursors of hepatocytes and cholangiocytes. ${ }^{146}$

HPCs are only activated after severe liver damage and are thought to represent a back up mechanism for hepatic regeneration. We hypothesise that, in view of their critical role in hepatic repair after excessive damage, HPCs should be able to protect themselves against toxic metabolites and xenobiotics, concentrations of which increase during reduced liver function. One mechanism of cellular protection is expression of efflux pumps that belong to the ATP binding cassette (ABC) superfamily of membrane transporters.

The ABC transporter family consists of approximately 48 members that have been divided into seven subclasses (A-G) based on their amino acid sequence homologies. Members of the Abcb (multidrug resistance proteins) subfamily that are expressed in the liver include efflux pumps for hydrophobic compounds and chemotherapeutic agents (Mdrla/b in rodents, gene symbol $A b c b l a / b$, MDRl in humans $),{ }^{89}$ a flippase that translocates phosphatidylcholine across the membrane (Mdr2, Abcb4, MDR3 in humans), ${ }^{10}$ and the export pump for bile salts Bsep $(A b c b 11) .{ }^{11}$ These transporters are all located in the canalicular membrane of hepatocytes, transporting their substrates into bile (reviewed in Hooiveld and colleagues ${ }^{12}$ ).

The Abcc (multidrug resistance associated protein) subfamily consists of 12 members, of which at least four (Mrpl, Mrp2, Mrp3, and Mrp6) are expressed in normal liver (reviewed by Borst and Oude Elferink ${ }^{7}$ ). Mrp2 (Abcc2) is present in the canalicular membrane of hepatocytes. Mrpl $(A b c c l)$ is located in the basolateral membrane but is expressed only at low levels in normal liver. Mrpl expression is induced in proliferating hepatocytes. ${ }^{13} \mathrm{Mrpl}$ and Mrp2 have a similar substrate specificity and transport glutathione S-conjugates, cysteinyl-leukotrienes, bilirubin glucuronides, oestrogen glucuronides, and glutathione disulphide. ${ }^{14}$ Hepatic expression of Mrp3, Mrp4, and Mrp6 has been reported recently. ${ }^{15}$ In normal liver, Mrp3 $(A b c c 3)$ is expressed in the basolateral membrane of pericentrally localised hepatocytes and in cholangiocytes. ${ }^{16}{ }^{17}$ Mrp3 can transport mono- and bivalent bile salts as well as glucuronide conjugates. ${ }^{18}{ }^{19}$ Its expression is increased during cholestasis and in conditions of conjugated or unconjugated hyperbilirubinaemia (Gunn rats and Mrp2 deficient mutant rats). ${ }^{160}$ Mrp4 (Abcc4) is an export

Abbreviations: $A B C$, ATP binding cassette; 2-AAF, 2-acetylaminofluorene; $\mathrm{CCl}_{4}$, carbon tetrachloride; CFDA, carboxyfluorescein diacetate; $C F$, carboxyfluorescein; HPC, hepatic progenitor cell; PBS, phosphate buffered saline; PHx, partial hepatectomy; RT-PCR, reverse transcription-polymerase chain reaction. 
pump for organic anions but is also capable of transporting cyclic nucleotides and nucleotide analogues. ${ }^{21} 22$ In normal liver, Mrp4 is expressed at low levels. ${ }^{15}$ However, enhanced hepatocellular concentrations of bile salts increase Mrp4 expression in liver. ${ }^{23}$ Mrp6 $(\mathrm{Abcc6})$ is expressed at high levels in normal liver, predominantly in the (baso)lateral membrane of hepatocytes. ${ }^{24}$ Its substrate specificity is presently less well defined.

A number of these transporters have been linked to cellular protection. Mdrlb functions as an efflux pump for toxins and may also have an antiapoptotic role. ${ }^{25}{ }^{26} \mathrm{Mrpl}$ is a transporter of leukotriene $\mathrm{C}_{4}$ and the glutathione conjugate of prostaglandin A2, factors involved in inflammation and cell cycle arrest. Moreover, Mrpl mediated transport of glutathione disulphide and glutathione conjugated 4-hydroxynonenal suggests that Mrpl functions as part of the cellular defence system against oxidative stress (reviewed by Renes and colleagues ${ }^{14}$ ). Mrp3 may have an important role in protecting cells from excessive amounts of endogenous bile salts by extruding these into blood. ${ }^{18} 19$

Two additional members of the ABC family that may be relevant for progenitor cell survival are Abcal and Bcrp (Abcg2). Abcal is highly expressed in fetal liver where its expression correlates with apoptotic areas. ${ }^{27}$ In adult life, Abcal is ubiquitously expressed in various tissues and organs. ${ }^{28}$ It is essential for HDL formation ${ }^{29}$ but its specific function in adult liver is currently unknown. Bcrp is expressed at relatively low levels in the apical membrane of hepatocytes. ${ }^{30}$ Expression of Bcrp can, in common with Mdrla/b and Mrpl, cause multidrug resistance. ${ }^{31}$ Bcrp has been demonstrated to have a cytoprotective role in a subgroup of haematopoietic stem cells. ${ }^{32}$

The expression profile of ABC transporters in the HPC compartment is not known. As these cells represent a potential proliferative reservoir of a severely damaged liver, we speculate that these cells must be well protected. We therefore studied $\mathrm{ABC}$ transporter expression in HPCs.

\section{MATERIALS AND METHODS}

\section{Animals}

Specified pathogen free male Wistar and Fisher 344 rats (130$170 \mathrm{~g}$ ) were purchased from Harlan-CPB, Zeist, the Netherlands, and were kept under routine laboratory conditions with a 12 hour light-dark cycle at the Central Animal Laboratory of the University of Groningen. Rats received standard laboratory chow and had free access to food and water. This study was approved by the Local Committee for Care and Use of Laboratory Animals.

\section{Animal experiments}

2-AAF/PHx induced oval cell activation in rats Seven days before PHx, 2-AAF pellets $(70 \mathrm{mg} /$ pellet over a 28 day release, $2.5 \mathrm{mg} /$ day; Innovative Research Inc., Sarasota, Florida, USA) or placebo pellets were placed subcutaneously in Wistar rats. PHx was performed according to the technique of Higgins and Anderson, removing two thirds of the liver. ${ }^{3}$ Sham operated animals underwent the same treatment protocol, including manipulation of the intestine and liver, but without hepatectomy. All surgery was performed under halothane anaesthesia. Nine days after surgery, livers were perfused with phosphate buffered saline (PBS) via the portal vein, excised, cut into small pieces, and snap frozen in liquid nitrogen for RNA isolation or frozen in cold 2-methyl-butane for immunohistochemistry. Tissue was stored at $-80^{\circ} \mathrm{C}$ prior to use.

\section{$\mathrm{PHx}$ induced hepatocyte proliferation in rats}

To determine transporter expression in proliferating hepatocytes, Wistar rats were either sham operated or underwent $\mathrm{PHx}^{33}$ At 24 hours post $\mathrm{PHx}$, hepatocytes were isolated using a two step collagenase perfusion technique, as described previously. ${ }^{34}$ Cell fractions were frozen in liquid nitrogen prior to RNA isolation.

\section{Isolation of hepatic cell fractions}

Specific hepatic cell fractions were isolated from male Fischer 344 rats. Cholangiocytes were isolated as described by Ishii and colleagues ${ }^{35}$ from five rats to obtain sufficient amounts of RNA. Oval cells were isolated from rats 12 days after $2-\mathrm{AAF} / \mathrm{CCl}_{4}$ treatment, as described by Petersen and colleagues. ${ }^{4}$ Hepatocytes were isolated according to Moshage and colleagues. ${ }^{34}$

\section{Cell culture}

The progenitor cell-like cell line RLF $\phi 13$ was a kind gift from Dr SS Thorgeirsson (Laboratory of Experimental Carcinogenesis, Division of Basic Sciences, National Cancer Institute, Bethesda, USA) and has been described previously. ${ }^{36}$ Cells were maintained in Ham's F12 (Invitrogen Life Technologies, Paisley, UK) supplemented with $10 \%$ fetal calf serum and $50 \mu \mathrm{g} / \mathrm{ml}$ gentamycin (Invitrogen Life Technologies). Cells were grown to $90-95 \%$ confluence prior to experiments in a humidified incubator at $37^{\circ} \mathrm{C} / 5 \% \mathrm{CO}_{2}$.

\section{Antibodies}

The mouse monoclonal antibody C219 (Dako, Glostrup, Denmark) was used for detection of all P-glycoproteins. The goat polyclonal anti-MRPl antibody SC-7774 (Santa Cruz Biotechnology, Santa Cruz, California, USA) was used for detection of Mrpl. The rabbit polyclonal anti-rat Mrp3 antibody was a kind gift from Dr H Suzuki (University of Tokyo, Tokyo, Japan)..$^{37}$ The OV-6 antibody was a kind gift from Dr S Sell (Albany Medical College, Albany, New York, USA). ${ }^{38}$

\section{Immunohistochemistry}

For immunohistological studies, $4 \mu \mathrm{m}$ sections were cut from frozen liver tissue. After drying, sections were fixed in acetone for 10 minutes at room temperature and washed in PBS, immediately before use. Primary antibodies were incubated for 30 minutes at room temperature. For monoclonal antibodies, a peroxidase staining method was used with secondary antibodies, preabsorbed with rat serum (Sigma, St Louis, Missouri, USA). For the rabbit polyclonal antibodies, the rabbit-EnVision staining method (Dako) was used. For the goat polyclonal antibody, the secondary step consisted of swine anti-goat IgG (Dako), followed by goat peroxidase-antiperoxidase (Dako). Secondary and tertiary antibodies were diluted in PBS containing 10\% normal rat serum. All incubation steps were performed for 30 minutes at room temperature and were followed by three washes in three changes of PBS for five minutes.

For semi quantitative estimations of protein expression, a series of dilutions of the primary antibodies were used $(1 / 10$ $1 / 30 ; 1 / 50 ; 1 / 100 ; 1 / 200 ; 1 / 500 ; 1 / 1000)$ and staining intensities were determined by microscopy. When staining was at the limit of detectability and disappeared at a higher dilution, it was evaluated as "critical staining". For each liver specimen, this critical staining was evaluated in each cell compartment separately. The dilution at which critical staining was observed is indicative for the relative up- or downregulation of protein levels in each liver cell compartment.

\section{RNA isolation and quantitative PCR}

Total RNA was isolated from tissue or cells using TRIzol (Invitrogen Life Technologies) followed by the SV Total RNA isolation system (Promega, Madison, Wisconsin, USA) according to the manufacturer's instructions. Reverse transcription (RT) was performed on $5 \mu \mathrm{g}$ of total RNA using random primers in a final volume of $75 \mu \mathrm{l}$ (Reverse Transcription System; Promega). 
Table 1 Sequences of polymerase chain reaction (PCR) primers and probes used for real time detection PCR analysis

\begin{tabular}{|c|c|}
\hline cDNA & Primer \\
\hline \multicolumn{2}{|l|}{ Mdrla } \\
\hline Sense & 5'-GCA GGT TGG CTG GAC AGA TT-3' \\
\hline Antisense & 5'-GGA GCG CAA TTC CAT GGA TA-3' \\
\hline Probe & 5' FAM-CCG CCA GAG TTC CCA GCA GCA TG-TAMRA 3' \\
\hline \multicolumn{2}{|l|}{$M d r l b$} \\
\hline Sense & 5'-AAA CAT GGC ACG TAA CCA AAG TT-3' \\
\hline Antisense & 5'-AAA ATG TGG CCC TGT TTA ATG ATT-3' \\
\hline Probe & $\begin{array}{l}\text { 5' FAM-CAC TGT TAA AGG TAA TTT CAT CAA GAC GAG AAG CCT } \\
\text { TC-TAMRA 3' }\end{array}$ \\
\hline \multicolumn{2}{|l|}{ Mdr2 } \\
\hline Sense & 5'-AGT TCA CGG GCG CAT CAA-3' \\
\hline Antisense & 5'-AAA AGA CAC TGG TGG CAC GTT-3' \\
\hline Probe & 5' FAM-CAT CAA GTT CAT TGG TTT CCA CAT CCA GC-TAMRA 3' \\
\hline \multicolumn{2}{|r|}{ ( } \\
\hline Sense & 5'-CCA AGC TGC CAA GGA TGC TA-3' \\
\hline Antisense & 5'-CCT TCT CCA ACA AGG GTG TCA-3' \\
\hline Probe & 5' FAM-CAT TAT GGC CCT GCC GCA GCA-TAMRA 3' \\
\hline \multicolumn{2}{|r|}{ 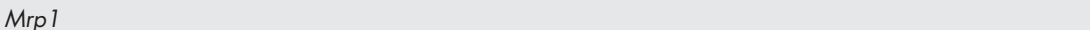 } \\
\hline Sense & 5'-GCC ACT GCC TCA TGC CTA TT-3' \\
\hline Antisense & 5'-GCA AGA CCT GAA GGC AAG ATA CA-3' \\
\hline Probe & 5' FAM-AGC CAC ATT TAT AGA GCC AAG CCA GAG CC-TAMRA 3' \\
\hline \multicolumn{2}{|r|}{ 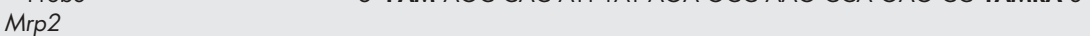 } \\
\hline Sense & 5'-GAC GAC GAT GAT GGG CTG AT-3' \\
\hline Antisense & 5'-CTT CTC ATG GCC AAG GAA GCT-3' \\
\hline Probe & 5' FAM-CCC ACC ATG GAG GAA ATC CCT GAG G-TAMRA 3' \\
\hline \multicolumn{2}{|r|}{ 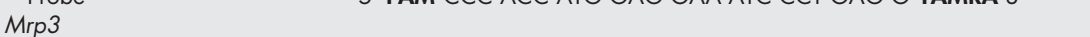 } \\
\hline Sense & 5'-TCC CAC TTC TCG GAG ACA GTA ACT-3' \\
\hline Antisense & 5'-CTT AGC ATC ACT GAG GAC CTT GAA-3' \\
\hline Probe & 5' FAM-CAG TGT CAT TCG GGC CTA CGG CC-TAMRA 3' \\
\hline \multicolumn{2}{|r|}{ 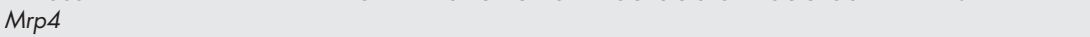 } \\
\hline Sense & 5'-TCA GTG TTG GAC AGA GAC AGT TAG TG-3' \\
\hline Antisense & 5'-CTT CTC CCG GAT TIT CTG TTG TAT-3' \\
\hline Probe & 5' FAM-TCA GTT CTC GGA TCC ACA TTT GCA GTT G-TAMRA 3' \\
\hline \multicolumn{2}{|r|}{ 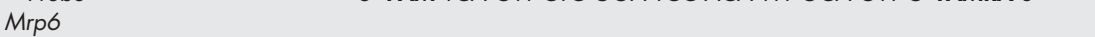 } \\
\hline Sense & 5'-CTC TCC CAT TGG CTT CTT TGA G-3' \\
\hline Antisense & 5'-GTC CAC ATC CAC TAT GTC CGT CT-3' \\
\hline Probe & 5' FAM-TCG GGA ACC TGC TGA ACC GTT TTT C-TAMRA 3' \\
\hline \multicolumn{2}{|r|}{ 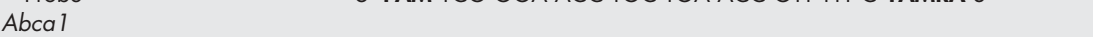 } \\
\hline Sense & 5'-CCC AGA GCA AAA AGC GAC TC-3' \\
\hline Antisense & 5'-GGT CAT CAT CAC TTT GGT CCT TG -3' \\
\hline Probe & $\begin{array}{l}\text { 5' FAM-AGA CTA CTC TGT CTC TCA GAC AAC ACT TGA CCA } \\
\text { AG-TAMRA } 3^{\prime}\end{array}$ \\
\hline \multicolumn{2}{|r|}{ 的 } \\
\hline Sense & 5'-CAG GTA GGC AAT TGT GAG GAA GA-3' \\
\hline Antisense & 5'-AAT CAG GGC ATC GAT CTG TCA-3' \\
\hline Probe & 5' FAM-CAT GCA AGC CAG GGC CAC ATG A-TAMRA 3' \\
\hline \multicolumn{2}{|r|}{ e } \\
\hline Sense & 5'-GCA GAT GTC CCG AGG ACA GA-3' \\
\hline Antisense & 5'-GGC AGT CCA GTC GAA GGT TCT-3' \\
\hline Probe & 5' FAM-CAG CCT GAC AGC CTG CCT GGT GA-TAMRA 3' \\
\hline \multicolumn{2}{|r|}{ 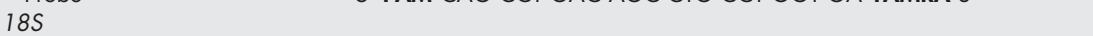 } \\
\hline Sense & $5^{\prime}$-CGG CTA CCA CAT CCA AGG A-3' \\
\hline Antisense & 5'-CCA ATT ACA GGG CCT CGA AA-3' \\
\hline Probe & 5' FAM-CGC GCA AAT TAC CCA CTC CCG A-TAMRA 3' \\
\hline
\end{tabular}

cDNA levels of the various genes were measured by real time polymerase chain reaction (PCR) using the ABI PRISM 7700 sequence detector (Applied Biosystems, Foster City, California, USA). Cycle numbers at which the sample fluorescence signal increases above a fixed threshold level $\left(\mathrm{C}_{\mathrm{T}}\right.$ value $)$ correlate inversely with mRNA levels. ${ }^{39}$ We used $4 \mu \mathrm{l}$ of a 20 -fold diluted cDNA in each PCR reaction in a final volume of $20 \mu \mathrm{l}$, containing $900 \mathrm{nM}$ of sense and antisense primers, $200 \mathrm{nM}$ of fluorogenic probe, $5 \mathrm{mM} \mathrm{MgCl}_{2}$, $\mathrm{KCl}$, Tris $\mathrm{HCl}, 0.2 \mathrm{mM}$ dATP, dCTP, dGTP, dTTP, and dUTP, and 0.5 U of AmpliTaq DNA polymerase (qPCR Core Kit; Eurogentech, Seraing, Belgium). Sequences of the primers and probes used are listed in table 1. Probes were labelled by a 5' FAM (6-carboxy-fluorescein) reporter and a 3' TAMRA (6-carboxy-tetramethyl-rhodamine) quencher. The PCR program was $95^{\circ} \mathrm{C}$ for 10 minutes, followed by 40 cycles of 15 seconds at $95^{\circ} \mathrm{C}$ and one minute at $60^{\circ} \mathrm{C}$. Each sample was analysed in duplicate. For quantification of
mRNA expression, calibration curves were constructed expressing the $\log$ of the input amount as $x$ and $\mathrm{C}_{\mathrm{T}}$ as $y$. 18S expression levels were used as endogenous controls.

Data resulting from the experimental groups are expressed as mean (SD). Differences between the four experimental groups in the 2-AAF/PHx experiment were determined by one way ANOVA analysis, with post hoc comparison by the Student-Newman-Keuls test (SPSS software). An unpaired Student's $t$ test was used to compare the means of the two groups. A p value $<0.05$ was considered significant.

\section{Flow cytometric detection of functional efflux}

Functional activity of the MRP transporter proteins was demonstrated essentially according to Van der Kolk and colleagues. ${ }^{40}$ Cells were exposed to $0.1 \mu \mathrm{M}$ carboxyfluorescein diacetate (CFDA) (Sigma) in combination with the Mrp inhibitor MK57l (kindly provided by Dr Ford-Hutchinson, 

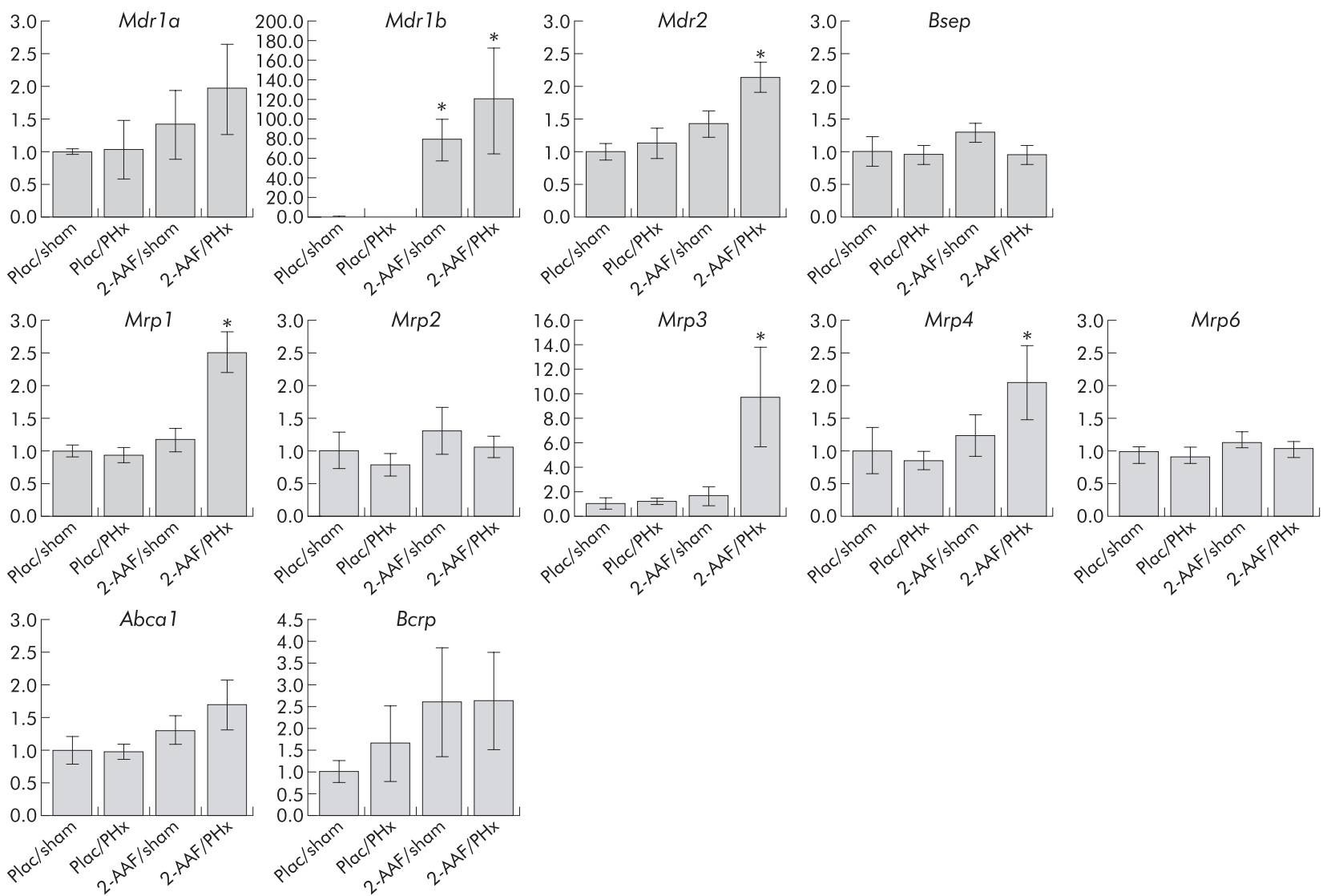

Figure 1 mRNA levels of ATP binding cassette $(A B C)$ transporter genes in rat liver after hepatic progenitor cell activation by 2 -acetylaminofluorene/partial hepatectomy (2- AAF/PHx) treatment. mRNA expression levels of various $A B C$ transporter genes were determined by real time detection reverse transcription-polymerase chain reaction, as described in materials and methods. Plac/sham, placebo pellet followed by sham operation; Plac/PHx: placebo pellet followed by $\mathrm{PHx}$; 2-AAF/sham, 2-AAF pellet followed by sham operation; 2-AAF/PHx, 2-AAF pellet followed by PHx. Data are means (SD), $n=3-5$ per group. * $p<0.05$.

Merck Sharp, Canada). Carboxyfluorescein (CF) fluorescence of 5000 cells was measured at a laser excitation wavelength of $488 \mathrm{~nm}$ through a $530 \mathrm{~nm}$ band pass filter using a FACScalibur flow cytometer (Becton Dickinson Medical Systems, Sharon, Massachusetts, USA). The efflux blocking factor of the inhibitor was expressed as median fluorescence intensity in inhibitor treated cells divided by median fluorescence intensity in untreated cells.

\section{RESULTS}

\section{Characteristics of partial hepatectomised rats}

Rats were treated with 2-AAF or placebo for seven days before undergoing PHx or sham operation. Mean body weight of the rats was 196 (13.1) g when 2-AAF or placebo pellets were placed and 242 (17.1) $\mathrm{g}$ at the time of surgery. There was no significant difference in body weight between rats receiving placebo pellets and those receiving 2-AAF containing pellets. On average, 7.6 (0.7) g of liver were excised during PHx. Animals undergoing 2- AAF/PHx treatment gained approximately $20 \mathrm{~g}$ in weight over the nine days after PHx compared with approximately $40 \mathrm{~g}$ for rats in the placebo/sham, placebo/PHx, and 2- AAF/sham groups. Liver weights from sham operated animals were used to calculate the per cent liver weight/body weight $(4.5 \%)$. From this, the percentage of liver removed from the partial hepatectomised rats was estimated to be $71 \%$.

\section{$A B C$ transporter gene expression in total liver samples} during progenitor cell activation

Figure 1 shows hepatic expression of the $\mathrm{ABC}$ genes in the four experimental groups, nine days after PHx or sham operation. Expression of $M d r l b$ mRNA was strongly increased in both groups treated with 2-AAF: 79 (20)-fold in 2-AAFtreated rats and 120 (53)-fold in 2- AAF/PHx treated rats (relative to $1.0(0.6)$ and $0.3(0.07)$ in the placebo/sham and placebo/PHx groups). In contrast, hepatic mRNA levels of Mdr2 (2.0-fold), Mrpl (2.5-fold), Mrp3 (10-fold), and Mrp4 (2.0-fold) were significantly increased only in 2-AAF/HPX treated rats. mRNA expression levels of Mdrla, Bsep, Mrp2, $M r p 6, A b c a l$, and Bcrpl were comparable for all four groups.

\section{Hepatic progenitor cells contain high levels of Mrp1 and Mrp3}

To determine the predominance of HPCs in rats treated with 2-AAF or 2-AAF/PHx, we performed immunohistochemical stainings using the OV6 antibody. Rats treated with 2-AAF alone showed mild proliferation of HPCs in their livers (fig 2A). Massive HPC proliferation was observed in livers of 2-AAF/HPx treated rats (fig $2 \mathrm{~B}$ ).

Next, localisation of selected $\mathrm{ABC}$ transporters was determined by immunohistochemistry. Figure $2 \mathrm{C}$ shows the clear canalicular staining pattern of C219, a monoclonal antibody recognising all P-glycoproteins, in normal rat liver. C219 staining intensity was much more pronounced in livers of 2-AAF and 2-AAF/PHx treated rats and was observed predominantly in periportal hepatocytes in both groups (shown for 2-AAF/HPx in fig 2D). Comparison of the staining patterns of OV6 (fig 2B) and C219 (fig 2D) in serial liver sections does not reveal any significant colocalisation of these two markers in HPCs. In an attempt to quantify the relative increase in Mdrlb protein levels, we performed immunohistochemical experiments with a series of dilutions of the primary antibody (C219) and determined the upper limit of dilution 

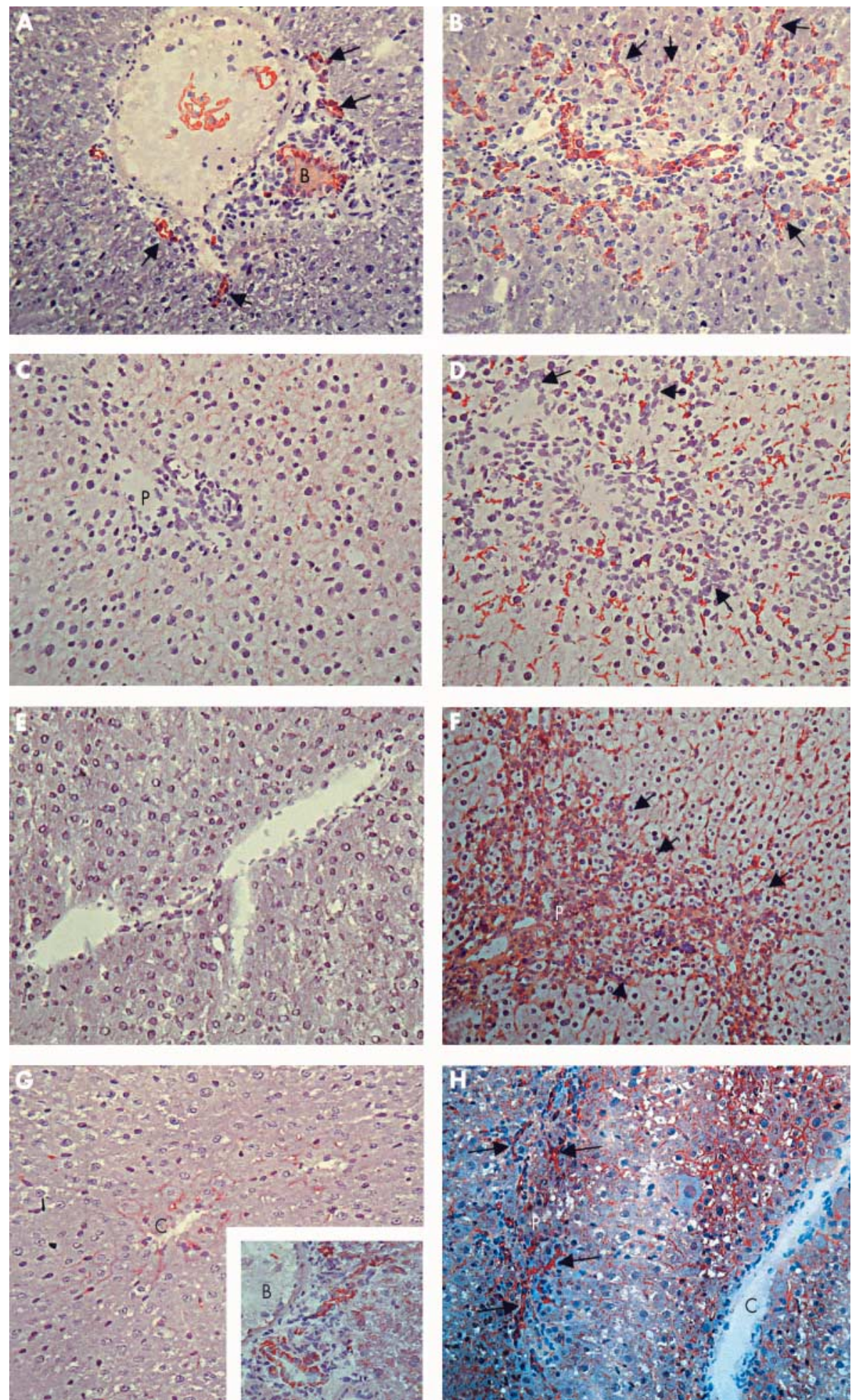

Figure 2 Immunohistochemical staining of $\operatorname{OV6}(A, B), C 219(C, D), \operatorname{Mrp} 1(E, F)$, and $\operatorname{Mrp3}(G, H)$ in control rat liver $(C, E, F)$,

2-acetylaminofluorene (2-AAF) treated (A) and 2-acetylaminofluorene/partial hepatectomy (2-AAF/PHx) treated rat liver (day 9) (B, D, F, H). Frozen liver sections were stained with primary antibodies directed against a common epitope in cytokeratin 14 and 19 (OV6, dilution 1/200), all p-glycoproteins (C219, dilution 1/5), Mrp1 (SC-7774, dilution 1/5), or Mrp3 (anti-Mrp3, dilution 1/500). Typical staining patterns of $n=3-5$ per group. $B$, bile duct, $P$, portal tract, $C$, central vein; arrows indicate progenitor cell reaction. In rats exposed to 2-AAF, OV6 stained the bile duct and a number of ductuli (A). In 2-AAF/PHx treated rats, a massively increased number of ductuli were apparent from intensive OV6 staining (B). In normal liver, C219 weakly stained the canalicular membrane of hepatocytes (C). In 2-AAF/PHx treated rat liver, C219 staining was increased (D). SC- 7774 did not stain normal liver (E) but significantly stained 2-AAF/PHx treated liver (F). In normal liver, anti-Mrp3 stained pericentral hepatocytes $(G)$ and bile ducts (insert in $(G)$ ). In treated rat liver there was additional staining of oval cells $(H)$.

for signal detection ("critical staining" level). Using this method, the increase in Mdrlb protein level expression for 2-AAF/PHx treated rats was estimated to be over 50-fold compared with controls.
In normal rat liver, expression of $\mathrm{Mrpl}$ is low. We were not able to detect a specific signal in immunohistochemical experiments using an antibody against Mrpl in these livers 

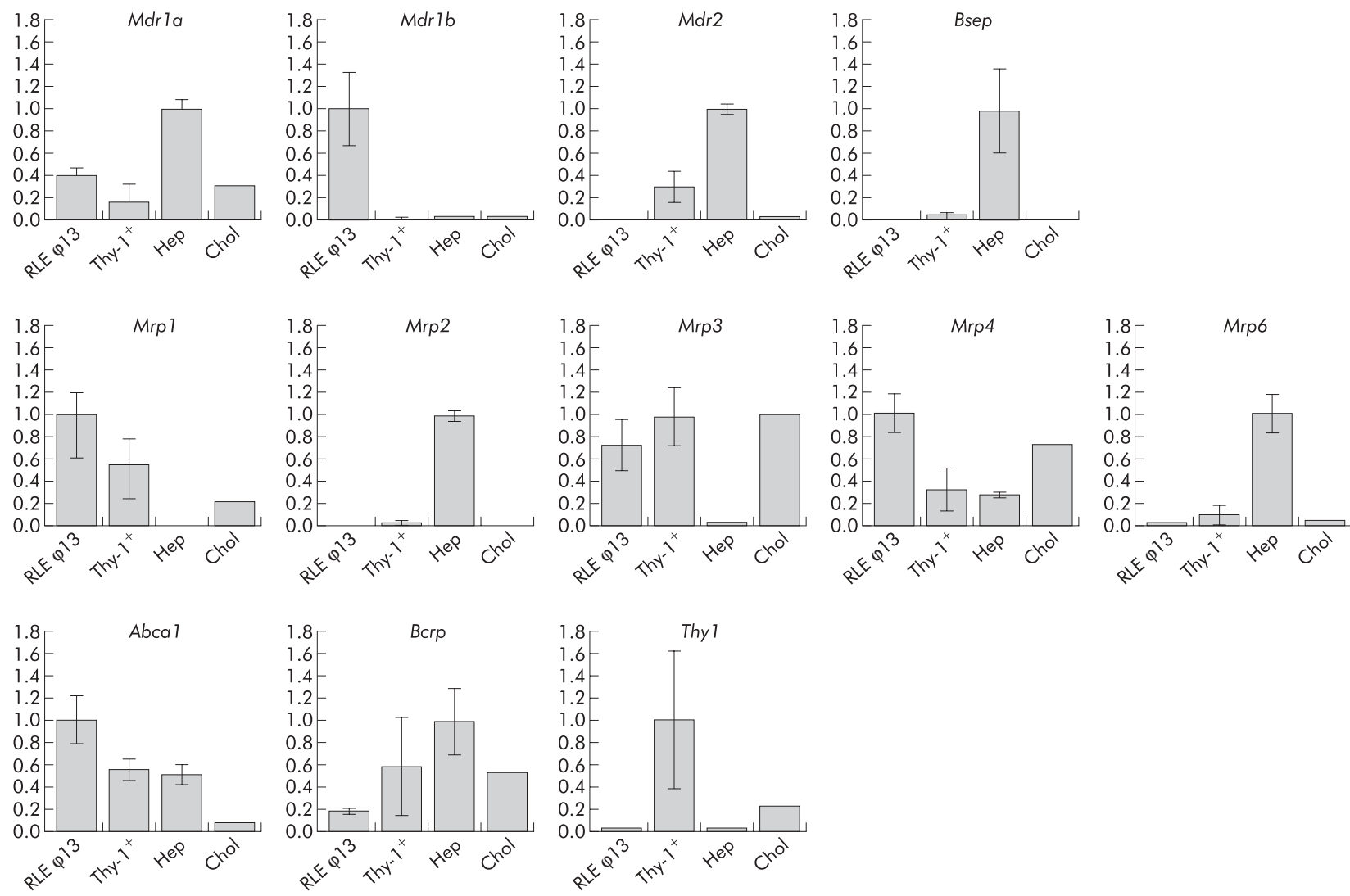

Figure 3 mRNA levels of ATP binding cassette (ABC) transporter genes in RLF $\phi 13$ cells, Thy- 1 positive cells $\left(\right.$ Thy- $\left.1^{+}\right)$, hepatocytes $($Hep), and cholangiocytes (Chol). Relative expression levels of various $A B C$ transporter genes in the different cell fractions were determined by real time detection reverse transcription-polymerase chain reaction, as described in materials and methods.

(fig 2E). However, in livers of 2-AAF/HPx treated rats, strong Mrpl specific staining was observed in HPCs.

In normal rat liver, low levels of Mrp3 are specifically found in the basolateral membrane of hepatocytes in the centrilobular zone (fig 2G) and bile ducts (fig 2G insert). In livers of 2-AAF/PHx treated rats, hepatocytes in the entire hepatic acinus contained Mrp3, with higher levels seen in pericentrally localised hepatocytes (fig $2 \mathrm{H}$ ). Notably, Mrp3 protein level was not increased in cholangiocytes. In addition, we observed high Mrp3 levels in HPCs in the livers of 2-AAF/HPx treated rats. The Mrp3 signal in HPCs was more intense than the signal in bile ductular cells.

\section{$A B C$ transporter gene expression in purified hepatic cell types}

To quantify cell type specific $\mathrm{ABC}$ transporter gene expression, we purified hepatocytes, cholangiocytes, and HPCs from whole liver and subjected these fractions to RT-PCR analysis. Thy- 1 positive cells were isolated from $2-\mathrm{AAF} / \mathrm{CCl}_{4}$ treated rats, 12 days after $\mathrm{CCl}_{4}$ exposure. These cells were compared with cholangiocytes and hepatocytes isolated from normal rats and with the progenitor cell-like cell line RLF $\phi$ 13. Figure 3 shows that, as expected, high level expression of Mdr2, Bsep, Mrp2, $M r p 6$, and Bcrp, and low level expression of Mdrlb, Mrpl, and Mrp3 were observed in hepatocytes. In contrast, cholangiocytes contained high levels of Mrp 3 and low levels of $M d r l b$, Mdr2, Bsep, Mrp2, Mrp6, and Abcal. Thy-l positive cells had a unique $\mathrm{ABC}$ phenotype in that they contained high levels of both Mrpl, Mrp3, and Abcal, a combination not observed in hepatocytes or cholangiocytes. For the other $\mathrm{ABC}$ transporters, the expression profile was mostly comparable with that of cholangiocytes. Comparison of transporter expression in RLF $\phi 13$ cells with that of Thy-1 positive cells showed that RLF $\phi 13$ cells had similar expression characteristics as Thyl positive cells. The exception in this respect was Mdrlb mRNA which was overexpressed in the RLF $\phi 13$ cell line.

\section{Mrp proteins function as active efflux pumps in RLF $\phi 13$ cells}

To confirm that expression of Mrpl and Mrp3 results in efficient efflux of Mrp substrates from HPCs, we performed flow cytometric assays using CFDA, which is intracellularly converted to the Mrp substrate CF. Incubation of RLF $\phi 13$ cells with CFDA resulted in a relative fluorescence of 25.0 (2.4) units. Performing the same experiment in the presence of the Mrp inhibitor MK571 ( 10 and $20 \mu \mathrm{M}$ ) caused retention of CF of 139.7 (2.2) and 224.9 (20.5) relative fluorescence units, respectively. Thus MK57l inhibited efflux 5.6- and 9.1- fold. A representative fluorescence histogram is shown in fig 4 .

\section{ABC transporter gene expression in proliferating hepatocytes}

In the experiments described above, the proliferating HPCs from the 2-AAF/HPx treated rats were compared with hepatocytes and cholangiocytes from normal liver. To determine whether the specific Mrpl, Mrp3, and Abcal phenotype is related to the proliferative state of these cells, we also determined the $\mathrm{ABC}$ expression profile of proliferating hepatocytes. Therefore, rats underwent PHx. Hepatocytes were isolated 24 hours later. At this time, most hepatocytes are going through cell division, as determined by BrdU incorporation (not shown). The ABC transporter profile of these cells is shown in table 2. Hepatocytes isolated from sham operated rats were used as controls. As described previously, proliferating hepatocytes contain high levels of Mdr lb. ${ }^{41}$ Apart from this characteristic, no strong differences in $\mathrm{ABC}$ transporter profiles were observed. 


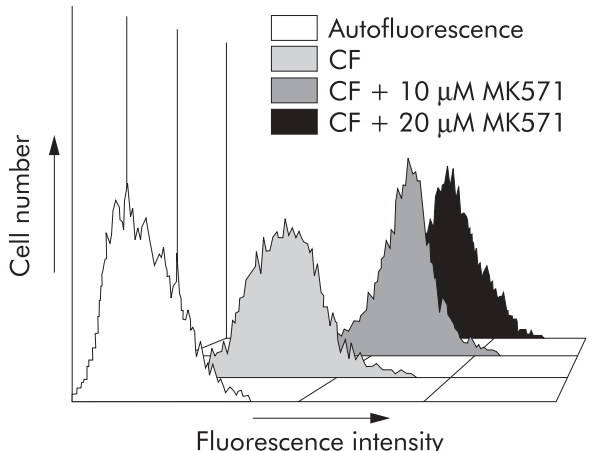

Figure 4 Fluorescence histogram. Representative fluorescence histogram of RLF $\phi 13$ cells showing carboxyfluorescein (CF) content after 60 minutes of incubation with or without the specific Mrp inhibitor MK571 $(10 \mu \mathrm{M}$ and $20 \mu \mathrm{M})$. Autofluorescence=control.

Table 2 Expression of ATP binding cassette transporter genes after $70 \%$ partial hepatectomy (PHx)

\begin{tabular}{lcc}
\hline Gene & 24 h sham & $24 \mathrm{~h} \mathrm{PHx}$ \\
\hline Mdrla & $1.00(0.37)$ & $1.29(0.26)$ \\
Mdrlb & $1.00(0.25)$ & $39.47(1.09)^{*}$ \\
Mdr2 & $1.00(0.29)$ & $2.08(0.36)^{*}$ \\
Bsep & $1.00(0.29)$ & $0.89(0.26)$ \\
Mrpl & $1.00(0.41)$ & $1.90(0.20)^{*}$ \\
Mrp2 & $1.00(0.41)$ & $0.84(0.08)$ \\
Mrp3 & $1.00(0.27)$ & $1.33(0.39)$ \\
Mrp4 & $1.00(0.13)$ & $2.15(0.35)^{*}$ \\
Mrp6 & $1.00(0.21)$ & $0.66(0.36)$ \\
Abcal & $1.00(0.40)$ & $1.37(0.23)$ \\
Bcrp & $1.00(0.65)$ & $0.69(0.13)$ \\
\hline mRNA levels, as determined by real time \\
detection polymerase chain reaction analysis. \\
Values for sham operated animals were set to 1. \\
Values are means (SD) of four experiments. \\
*p<0.05.
\end{tabular}

\section{DISCUSSION}

In this study, we demonstrated that rat HPCs are characterised by high level expression of the ABC transporters Mrpl and Mrp3. These transporters may protect this important cell population under toxic conditions in which these cells are required for repopulation of the liver.

In our in vivo experiments, we induced proliferation of HPCs by treating rats with 2-AAF followed by PHx. Concurrently, proliferation of hepatocytes is inhibited and repopulation of the liver depends on proliferation and differentiation of hepatic progenitor cells. Nine days after $\mathrm{PHx}$, mRNA levels of selected ABC transporters in whole liver samples was determined by real time RT-PCR. Cell specific expression was analysed by immunohistochemistry. We observed a particularly strong (up to 120-fold) increase in hepatic Mdrlb mRNA levels after 2-AAF/PHx treatment compared with placebo/sham operated rats. A comparable increase (up to 80-fold) of $M d r I b$ mRNA levels was however also observed in rats treated with 2-AAF alone where the number of proliferating HPCs was significantly lower. Immunohistochemistry showed that Mdrl protein in livers of 2-AAF/PHx treated rats was confined to the remaining hepatocytes rather than HPCs. Apparently, 2-AAF strongly induces expression of this gene. These results are in agreement with in vitro experiments that showed that 2-AAF causes an increase in expression of $M d r l b$ in cultured rat hepatocytes and rat hepatoma cell lines, as well as with previous in vivo experiments in rats. ${ }^{42-44}$ Deng and colleagues ${ }^{45}$ have recently elucidated the intracellular signal transduction pathway involved in upregulation of $M d r l b$
mRNA levels by 2-AAF in an in vitro model. They demonstrated that transcription of $M d r l b$ is induced by nuclear factor $\mathrm{\kappa B}$. Activation of nuclear factor $\mathrm{\kappa B}$ is the ultimate result of oxidative stress generated by 2 -AAF. ${ }^{45}$ Moreover, 2 -AAF has been demonstrated to increase p53 expression. ${ }^{2}$ p53, in turn, can induce $M d r l b$ expression. ${ }^{46}$ The strong C219 staining pattern in rats treated with 2 -AAF alone can thus, at least in part, be explained by direct effects of 2-AAF on hepatocytes. After 2-AAF/PHx treatment, when there is extensive oval cell activation, Mdrlb protein expression seemed to be confined to periportal hepatocytes and did not occur in the OV-6 positive cell compartment or in bile duct epithelial cells. Notably, this observation contrasts with the human situation. In liver biopsies of patients with submassive necrosis, chronic hepatitis C, or primary biliary cirrhosis, we observed greatly increased expression of MDRl not only in the remaining hepatocytes but also in regenerating ductules that represent putative progenitor cells (Ros et al, in press). The reason for this difference is not known at present.

Strongly increased expression of Mrpl (2.5-fold) and Mrp3 ( 10 -fold) was seen in livers of $2-\mathrm{AAF} / \mathrm{PHx}$ treated rats. In contrast with Mdrlb, this increase was not observed in 2- AAF/sham treated rats. In normal liver, both Mrpl and Mrp3 are expressed at low levels with Mrp3 localised only in pericentral hepatocytes and cholangiocytes. In 2-AAF/PHx treated rats, both Mrpl and Mrp3 were predominantly detected in HPCs. To further substantiate that Mrpl and Mrp3 are indeed markers for HPCs, we determined the expression profiles of ABC transporters in purified cell fractions enriched in hepatocytes, cholangiocytes, or HPCs (Thy-l positive cells). In addition, we included the hepatic progenitor cell-like RLF $\phi 13$ cell line in these studies. Compared with hepatocytes, freshly isolated Thy-1 positive cells showed high level expression of Mrpl and Mrp3 and low expression of Mdr2, Bsep, Mrp2, and Mrp6. Thus the ABC transporter phenotype of HPCs resembles that of cholangiocytes, except for Mrpl and Abcal, which are highly expressed in progenitor cells but not in cholangiocytes. The ABC transporter phenotype of RLF $\phi 13$ cells resembles that of freshly isolated Thy-l positive cells, except for $M d r l b$ which is highly expressed in RLF $\phi 13$ cells only. However, high expression levels of Mdrlb are frequently observed in cultured cells ${ }^{47}$ and cannot be regarded as a cell type specific feature. Our functional assays using specific Mrp inhibitors confirmed that RLF $\phi 13$ cells are indeed able to efficiently extrude Mrp specific substrates.

High expression levels of Mrpl and Mrp3 observed in rat HPCs is in agreement with the expression pattern seen in severely diseased human liver in which we also observed high level expression of MRP1 and MRP3 in regenerating ductules, the site of progenitor cells (Ros et al, in press).

It has recently been shown that primitive haematopoietic stem cells highly express Bcrp, the breast cancer resistance protein. ${ }^{48}$ As HPCs display primitive features, we speculated that these cells may also have high Bcrp expression. However, in the 2-AAF/PHx model, Bcrp mRNA expression was not induced. Neither RLF $\phi 13$ nor Thy-1 positive cells were particularly rich in Bcrp. Thus in contrast with haematopoietic (side population) cells, Bcrp is not highly expressed in HPCs.

Taken together, these data demonstrate that HPCs have high expression levels of functional Mrpl and Mrp3. The current view is that Mrpl functions mainly as a cellular efflux pump of cysteinyl-leukotrienes and glutathione-S-conjugates and Mrp3 as a pump for glucuronides and mono- and divalent bile salts. Thus Mrpl and Mrp3 may have a role in removing both exogenous and endogenous toxic drugs/metabolites from progenitor cells.

In conclusion, our findings show that strong induction of Mdrlb in the 2-AAF/PHx model is confined to hepatocytes while expression of Mrpl and Mrp3 occurs mainly in HPCs. HPCs appear to be well protected by these ABC transporters which may enable them to survive in conditions associated 
with excessive metabolic stress and serve as a proliferative reservoir when the liver is severely damaged.

\section{ACKNOWLEDGEMENT}

The authors thank Dr SS Thorgeirsson for providing the RLF $\phi 13$ cell line and Dr H Suzuki and Dr S Sell for proving the Mrp3 and OV6 antibodies. This study was supported by grant NWO 902-23-191 of the Netherlands Organization for Scientific Research.

\section{Authors' affiliations}

J E Ros, M Geuken, R Havinga, F Kuipers, K N Faber, P L M Jansen, Groningen University Institute for Drug Exploration (GUIDE), Centre for the Study of Liver, Digestive, and Metabolic Diseases, University Hospital Groningen, Groningen, the Netherlands

T A D Roskams, Department of Liver Pathology, University of Leuven, Leuven, Belgium

P L Splinter, N F LaRusso, Centre for Basic Research in Digestive Diseases, Division of Gastroenterology and Internal Medicine, Mayo Medical School, Rochester, Minnesota 55905, USA

B E Petersen, Department of Pathology, Immunology, and Laboratory Medicine, University of Florida College of Medicine, Gainesville, Florida 32610, USA

D $M$ van der Kolk, Division of Haematology, Department of Interna Medicine, University Hospital Groningen, Groningen, the Netherlands M Müller, Division of Nutrition, Metabolism, and Genomics, Wageningen University, Wageningen, the Netherlands

\section{REFERENCES}

1 Evarts RP, Nagy $\mathrm{P}$, Nakatsukasa $\mathrm{H}$, et al. In vivo differentiation of rat liver oval cells into hepatocytes. Cancer Res 1989:49:1541-7.

2 Trautwein C, Will M, Kubicka S, et al. 2-Acetaminofluorene blocks cell cycle progression after hepatectomy by p21 induction and lack of cyclin Expression. Oncogene 1999;18:6443-53.

3 Theise ND, Saxena R, Portmann BC, et al. The canals of Hering and hepatic stem cells in humans. Hepatology 1999;30:1425-33

4 Petersen BE, Goff JP, Greenberger JS, et al. Hepatic oval cells express the hematopoietic stem cell marker Thy- 1 in the rat. Hepatology 1998:27:433-45.

5 Petersen BE, Zajac VF, Michalopoulos GK. Hepatic oval cell activation in response to injury following chemically induced periportal or pericentral damage in rats. Hepatology 1998;27:1030-8.

6 Golding M, Sarraf CE, Lalani EN, et al. Oval cell differentiation into hepatocytes in the acetylaminofluorene-treated regenerating rat liver. Hepatology 1995;22:1243-53.

7 Borst P, Oude Elferink RPJ. Mammalian ABC transporters in health and disease. Annu Rev Biochem 2002;71:537-92.

8 Sharom FJ. The P-glycoprotein efflux pump: how does it transport drugs? J Membr Biol 1997;160:161-75.

9 Schinkel AH, Wagenaar E, van Deemter L, et al. Absence of the mdrla P- glycoprotein in mice affects tissue distribution and pharmacokinetics of dexamethasone, digoxin, and cyclosporin A. J Clin Invest 1995; 96 : 1698-705

10 Smit JJM, Schinkel AH, Oude Elferink RPJ, et al. Homozygous disruption of the murine $\mathrm{mdr} 2 \mathrm{P}$-glycoprotein gene leads to a complete absence of phospholipid from bile and to liver disease. Cell 1993;75:451-62.

11 Gerloff T, Stieger B, Hagenbuch B, et al. The sister of P-glycoprotein represents the canalicular bile salt export pump of mammalian liver. J Biol Chem 1998;273:10046-50.

12 Hooiveld GJEJ, van Montfoort JE, Meijer DKF, et al. Function and regulation of ATP-binding cassette transport proteins involved in hepatobiliary transport. Eur J Pharm Sci 2001;12:525-43.

13 Roelofsen H, Hooiveld GJEJ, Koning H, et al. Glutathione S-conjugate transport in hepatocytes entering the cell cycle is preserved by a switch in expression from the apical MRP2 to the basolateral MRP1 transporting protein. J Cell Sci 1999;1 12:1395-404

14 Renes J, de Vries EGE, Jansen PLM, et al. The (patho)physiological functions of the MRP family. Drug Resist Updat 2000;3:289-302.

$15 \mathrm{Kool} M$, de Haas M. Scheffer GL, et al. Analysis of expression of CMOAT (MRP2), MRP3, MRP4, and MRP5, homologues of the multidrug resistance-associated protein gene (MRPl) in human cancer cell lines. Cancer Res 1997;57:3537-47

16 Donner MG, Keppler D. Up-regulation of basolateral multidrug resistance protein 3 (Mrp3) in cholestatic rat liver. Hepatology $2001: 34: 351-9$.

17 Soroka CJ, Lee JM, Azzaroli F, et al. Cellular localization and up-regulation of multidrug resistance-associated protein 3 in hepatocytes and cholangiocytes during obstructive cholestasis in rat liver. Hepatology 2001;33:783-91.

18 Hirohashi T, Suzuki H, Takikawa H, et al. ATP-dependent transport of bile salts by rat multidrug resistance-associated protein 3 (Mrp3). J Biol Chem 2000;275:2905-10.

19 Hirohashi T, Suzuki H, Sugiyama Y. Characterization of the transport properties of cloned rat multidrug resistance-associated protein 3 (MRP3). J Biol Chem 1999;274:15181-5.
20 Hirohashi T, Suzuki H, lto K, et al. Hepatic expression of multidrug resistance- associated protein-like proteins maintained in Eisai hyperbilirubinemic rats. Mol Pharmacol 1998;53:1068-75.

21 Schuetz JD, Connelly MC, Sun D, et al. MRP4: A previously unidentified factor in resistance to nucleoside-based antiviral drugs. Nat Med 1999;5: 1048-51

22 Chen ZS, Lee K, Kruh GD. Transport of cyclic nucleotides and estradiol 17-beta-D-glucuronide by multidrug resistance protein 4 . Resistance to 6-mercaptopurine and 6- thioguanine. J Biol Chem 2001;276:3374754.

23 Schuetz EG, Strom S, Yasuda K, et al. Disrupted bile acid homeostasis reveals an unexpected interaction among nuclear hormone receptors, transporters, and cytochrome P450. J Biol Chem 2001;276:39411-18.

24 Madon J, Hagenbuch B, Landmann L, et al. Transport function and hepatocellular localization of mrp6 in rat liver. Mol Pharmacol 2000:57:634-41.

25 Johnstone RW, Cretney E, Smyth M. P-glycoprotein protects leukemia cells against caspase-dependent, but not caspase-independent, cell death. Blood 1999;93:1075-85

26 Thevenod F, Friedmann JM, Katsen AD, et al. Up-regulation of multidrug resistance $\mathrm{P}$-glycoprotein via nuclear factor-kappaB activation protects kidney proximal tubule cells from cadmium- and reactive oxygen species-induced apoptosis. J Biol Chem 2000;275: 1887-96.

27 Hamon $Y$, Broccardo $C$, Chambenoit $O$, et al. $A B C 1$ promotes engulfment of apoptotic cells and transbilayer redistribution of phosphatidylserine. Nat Cell Biol 2000;2:399-406.

28 Langmann T, Klucken J, Reil M, et al. Molecular cloning of the human ATP-binding cassette transporter 1 (hABC 1): evidence for sterol-dependent regulation in macrophages. Biochem Biophys Res Commun 1999:257:29-33.

29 Brooks-Wilson A, Marcil M, Clee SM, et al. Mutations in $A B C 1$ in Tangier disease and familial high-density lipoprotein deficiency. Nat Genet 1999;22:336-45.

30 Maliepaard $\mathbf{M}$, Scheffer GL, Faneyte IF, et al. Subcellular localization and distribution of the breast cancer resistance protein transporter in normal human tissues. Cancer Res 2001;61:3458-64.

31 Doyle LA, Yang W, Abruzzo LV, et al. A multidrug resistance transporter from human MCF-7 breast cancer cells. Proc Natl Acad Sci U S A 1998;95:15665-70.

32 Zhou S, Morris JJ, Barnes Y, et al. Bcrpl gene expression is required for normal numbers of side population stem cells in mice, and confers relative protection to mitoxantrone in hematopoietic cells in vivo. Proc Natl Acad Sci U S A 2002:99:12339-44.

33 Higgins GM, Anderson RM. Experimental pathology of the liver I. Restoration of the liver of the white rat following partial surgical removal. Arch Pathol 1931;12:186-202

34 Moshage H, Casini A, Lieber CS. Acetaldehyde selectively stimulates collagen production in cultured rat liver fat-storing cells but not in hepatocytes. Hepatology 1990;12:511-18.

35 Ishii $M$, Vroman B, LaRusso NF. Isolation and morphologic characterization of bile duct epithelial cells from normal rat liver. Gastroenterology 1989;97:1236-47.

36 Potten CS, ed. Grisham JW, Thorgeirsson SS. Liver Stem Cells. London: Academic Press, 1997:233-82.

37 Ogawa K, Suzuki H, Hirohashi T, et al. Characterization of inducible nature of MRP3 in rat liver. Am J Physiol Gastrointest Liver Physiol 2000:278:G438-46.

38 Dunsford HA, Sell S. Production of monoclonal antibodies to preneoplastic liver cell populations induced by chemical carcinogens in rats and to transplantable Morris hepatomas. Cancer Res 1989;49:4887-93

39 Heid CA, Stevens J, Livak KJ, et al. Real time quantitative PCR. Genome Res 1996:6:986-94

40 Van der Kolk DM, de Vries EGE, Koning JA, et al. Activity and expression of the multidrug resistance proteins MRP1 and MRP2 in acute myeloid leukemia cells, tumor cell lines, and normal hematopoietic CD34+ peripheral blood cells. Clin Cancer Res 1998;4:1727-36.

41 Vos TA, Ros JE, Havinga R, et al. Regulation of hepatic transport systems involved in bile secretion during liver regeneration in rats. Hepatology 1999.29.1833-9.

42 Hill BA, Brown PC, Preisegger $\mathrm{KH}$, et al. Regulation of mdr $1 \mathrm{~b}$ gene expression in Fischer, Wistar and Sprague-Dawley rats in vivo and in vitro. Carcinogenesis 1996;17:451-7.

43 Thorgeirsson SS, Huber BE, Sorrell S, et al. Expression of the multidrug-resistant gene in hepatocarcinogenesis and regenerating rat liver. Science 1987:236:1120-2.

44 Teeter LD, Estes M, Chan JY, et al. Activation of distinct multidrug-resistance (P-glycoprotein) genes during rat liver regeneration and hepatocarcinogenesis. Mol Carcinog 1993;8:67-73.

45 Deng L, Lin-Lee YC, Claret FX, et al. 2-Acetylaminofluorene up-regulates rat $\mathrm{mdr} 1 \mathrm{~b}$ expression through generating reactive oxygen species that activate NF-kappa B pathway. J Biol Chem 2001:276:413-20.

46 Lecureur V, Thottassery JV, Sun D, et al. Mdr lb facilitates p53-mediated cell death and $\mathrm{p} 53$ is required for Mdrlb upregulation in vivo. Oncogene 2001;20:303-13

47 Schuetz JD, Schuetz EG. Extracellular matrix regulation of multidrug resistance in primary monolayer cultures of adult rat hepatocytes. Cell Growth Differ 1993:4:31-40.

48 Zhou S, Schuetz JD, Bunting KD, et al. The ABC transporter Bcrpl/ABCG2 is expressed in a wide variety of stem cells and is a molecular determinant of the side- population phenotype. Nat Med 2001;7:1028-34 